\title{
Skeletal Muscle Mass and Architecture of the World's Strongest Raw Powerlifter: A Case Study
}

\author{
Takashi Abe, ${ }^{1,}$ Samuel L. Buckner, ${ }^{1}$ Kevin T. Mattocks, ${ }^{1}$ Matthew B. Jessee, ${ }^{1}$ Scott J. Dankel, ${ }^{1}$ J. Grant \\ Mouser, ${ }^{1}$ Zachary W. Bell, ${ }^{1}$ and Jeremy P. Loenneke ${ }^{1}$ \\ ${ }^{1}$ Department of Health, Exercise Science \& Recreation Management, Kevser Ermin Applied Physiology Laboratory, The University of Mississippi, University, MS 38677, USA \\ "Corresponding author: Takashi Abe, PhD, Department of Health, Exercise Science \& Recreation Management, The University of Mississippi, 224 Turner Center, University, MS \\ 38677, USA. Tel: +1-6629155521, E-mail: t12abe@gmail.com
}

Received 2017 September 14; Revised 2018 January 26; Accepted 2018 February 17.

\begin{abstract}
Introduction: World powerlifting records within the super heavyweight class are typically held by those with not only the greatest absolute muscle strength but also the greatest amount of skeletal muscle mass (SM).

Case Presentation: We examined the absolute and relative SM and muscle architecture of a 30 year old drug-free raw (i.e. without the use of powerlifting supportive equipment) powerlifter (1.84 $\mathrm{m}$ standing height and $183.1 \mathrm{~kg}$ body mass) who competes in the super heavyweight division and holds world records in the squat ( $477.5 \mathrm{~kg}$ ), deadlift (392.5 kg), and total (1105 kg). Because the MRI magnet is too small for very large athletes, we used an ultrasound prediction equation to estimate SM. We also used ultrasound to determine muscle architecture (isolated muscle thickness, pennation angle and fascicle length). This powerlifter had large values of fat-free mass $(138.6 \mathrm{~kg})$ and total SM $(58.0 \mathrm{~kg})$ compared with previously published values. When calculating the powerlifting performance per unit SM, this lifter not only had high levels of absolute strength but also had high levels of relative strength per unit SM, particularly in the squat. Similarly, muscle thickness and pennation angle of the vastus lateralis were close to the highest values previously reported in the literature.

Conclusions: These results suggest that this powerlifter may be close to a physiologic limit with respect to muscle size and geometry.

Keywords: Muscles, Ultrasonography, Human Limitation
\end{abstract}

\section{Introduction}

Powerlifting comprises of three separate barbell-based lifts: squat, bench press, and the deadlift. Powerlifters attempt to lift the maximum weight possible for each of those lifts in order to form a total. This total is then made relative to body mass using the Wilks formula in order to determine the overall best lifter. Although there are eleven separate weight classes within male powerlifting, the world records in the super heavyweight class typically belong to the athletes with the greatest absolute muscular strength as well as the greatest skeletal muscle mass (SM) (1).

Previous studies in humans have often used fat-free mass (body mass without fat) to estimate total SM in the body and have reported that the upper limit of fat-free mass accumulation may be approximately $120 \mathrm{~kg}$ in males $(2,3)$. However, it is important to measure SM given that the ratio of SM to fat-free mass is often inconsistent among individual athletes $(4,5)$. Magnetic resonance imaging (MRI) is the recognized gold standard to measure SM (6). Unfortunately, it is impossible to measure SM in a large sized athlete because the space within the MRI magnet is limited (5). Therefore, with the reference value being MRI, we developed prediction equations to estimate SM from ultrasound measured muscle thickness (7). Furthermore, large-size muscles in athletes may possess differences in architectural characteristics with a greater pennation angle limiting changes in fascicle length (8) or a greater fascicle length limiting changes in pennation angle (9). The aim of this case study was to examine both the absolute and relative SM as well as the muscle architecture of the strongest raw powerlifter in the world and to compare these results with previously reported data.

Copyright (c) 2018, Asian Journal of Sports Medicine. This is an open-access article distributed under the terms of the Creative Commons Attribution-NonCommercial 4.0 International License (http://creativecommons.org/licenses/by-nc/4.0/) which permits copy and redistribute the material just in noncommercial usages, provided the original work is properly cited 


\section{Case presentation and Discussion}

\subsection{Competition History and Methodological Approach}

This case study reports the SM and strength of a 30 year old drug-free raw (i.e. without the use of powerlifting supportive equipment) powerlifter who competes in the super heavyweight division and holds world records in the squat (477.5 kg), deadlift (392.5 kg), and total (1105 kg).

This individual has won 3 National Championships as well as 4 World Championships with his most recent victory at the IPF World Classic Championships in Belarus. There he totaled $1090 \mathrm{~kg}$ across all three lifts at a body mass of $181.2 \mathrm{~kg}$ (Wilks of 585.98). His best squat, bench press, and deadlift that day were $470 \mathrm{~kg}, 242.5 \mathrm{~kg}$, and $377.5 \mathrm{~kg}$, respectively. This study was approved by the University's institutional review board.

Muscle thickness was measured by B-mode ultrasound (Logiq e, L4-12t probe, GE, Fairfield, CT, USA) at nine sites (abdomen, anterior forearm, anterior and posterior upper arm, anterior and posterior upper-leg, anterior and posterior lower leg, and subscapula) on the right side of the body (Table 1) as described previously (10). This testing was carried out at least 24 hours after the last training session. From these measurements, total SM was estimated using the prediction equation by Sanada et al. (7). SM index was calculated as SM (kg) divided by height squared $\left(\mathrm{m}^{2}\right)$. Testretest reliability of muscle thickness measurements (ICC, SEM and minimal difference) was determined as described previously (11).

\begin{tabular}{lcc}
\hline Table 1. Subcutaneous Fat Thickness and Skeletal Muscle & \multicolumn{2}{c}{ Thickness at Nine Sites } \\
\hline & \multicolumn{2}{c}{ Thicks, cm } \\
\cline { 2 - 3 } & 0.67 & 4.80 \\
\hline Forearm anterior & 0.85 & 6.29 \\
\hline Upper-arm anterior & 0.58 & 7.13 \\
\hline Upper-arm posterior & 3.56 & 2.87 \\
\hline Abdomen & 1.41 & 5.82 \\
\hline Subscapula & 0.71 & 9.79 \\
\hline Upper-leg anterior & 0.70 & 10.82 \\
\hline Upper-leg posterior & 0.49 & 3.34 \\
\hline Lower-leg anterior & 0.62 & 8.71 \\
\hline Lower-leg posterior & & \\
\hline
\end{tabular}

Muscle architecture of the vastus lateralis (midway between the lateral condyle and greater trochanter of the femur) was determined using B-mode ultrasound as described previously (12). Ultrasound images were obtained from a linear array probe held perpendicularly for the measurement of muscle thickness and parallel for the measurement of pennation angle and fascicle length. The distance between the subcutaneous adipose tissue-muscle interface and the deep aponeurosis of the vastus lateralis was accepted as the vastus lateralis muscle thickness. Pennation angle was determined as the angle between the echo from the deep aponurosis of the vastus lateralis and the interspaces among the fascicles of the vastus lateralis. The length of the fascicle across the deep and superficial aponeurosis was directly measured using ultrasound images on a display of the ultrasound system (12).

Subcutaneous fat thickness was measured using the same ultrasound images as described above. Body density was estimated from subcutaneous fat thickness using an ultrasound-derived prediction equation (10). Percent body fat was calculated from body density using the Brozek, Grande, Anderson, and Keys's equation (13) and was used to calculate total fat mass. Fat-free mass was calculated as the difference between body mass and total fat mass. Body mass and standing height were measured to the nearest $0.1 \mathrm{~kg}$ and $0.1 \mathrm{~cm}$, respectively, using a stadiometer and an electronic weight scale. Body mass index was calculated as body mass ( $\mathrm{kg}) /$ standing height squared $\left(\mathrm{m}^{2}\right)$.

\subsection{Body Fat and Fat-Free Mass}

Standing height, body mass and body mass index were $1.84 \mathrm{~m}, 183.1 \mathrm{~kg}$ and $54.1 \mathrm{~kg} / \mathrm{m}^{2}$, respectively. Ultrasound estimated percent body fat was $24.3 \%$, and calculated fat-free mass was $138.6 \mathrm{~kg}$. Several studies have investigated percent fat and fat-free mass using the underwater weighing technique on professional American football players (14), professional basketball players (14), and Japanese professional sumo wrestlers (2). The offensive linemen and defensive linemen averaged body fat percentages of $15.5 \%$ and $18.7 \%$, respectively, with an estimated fat-free mass of 95.4 $\mathrm{kg}$ and $97.7 \mathrm{~kg}$, respectively. The largest football player in that study had $107 \mathrm{~kg}$ of fat-free mass (14). A professional basketball player who played the center position had 100.7 $\mathrm{kg}$ of fat-free mass (15). Similarly, seven elite Japanese professional sumo wrestlers averaged $26.1 \%$ of percent body fat and $109 \mathrm{~kg}$ of fat-free mass. The largest fat-free mass in the sumo wrestlers was $121.3 \mathrm{~kg}$, which was the largest fat-free mass value in the published literature (2). Compared with the previously published data, the $138.6 \mathrm{~kg}$ of fat-free mass in this case study was approximately $17 \mathrm{~kg}$ higher than that of the previously reported sumo wrestler (2). 


\subsection{Muscle Mass and Powerlifting Performance}

In this study, total SM and SM index were $58.0 \mathrm{~kg}$ and $17.2 \mathrm{~kg} / \mathrm{m}^{2}$, respectively. Recently, we have reported on the relationship between SM index and body mass in male athletes and recreationally active men. The relationship was parabolic, reaching a plateau (approximately $17 \mathrm{~kg} / \mathrm{m}^{2}$ ) beyond $120 \mathrm{~kg}$ of body mass (5). Only four of the 95 largesized male athletes had a SM index of more than $15 \mathrm{~kg} / \mathrm{m}^{2}$ (5). Further, our previous study investigating the SM of 20 elite male powerlifters (including 7 world and/or national champions) reported that the six super-heavyweight powerlifters averaged 51.6 (SD 4.3) kg for total SM and 15.4 (SD 1.2) $\mathrm{kg} / \mathrm{m}^{2}$ for $\mathrm{SM}$ index, with the largest athlete being at $59.3 \mathrm{~kg}$ and $16.5 \mathrm{~kg} / \mathrm{m} 2$, respectively(1). Thus, the SM and SM index values of the powerlifter reported in this case study are close to the highest values in the published literature.

Using this lifter's most recent competition, we calculated the powerlifting performance per unit of $\mathrm{SM}(\mathrm{kg})$. His relative strength was $8.10 \mathrm{~kg} / \mathrm{kg}$ for the squat, $4.18 \mathrm{~kg} / \mathrm{kg}$ for the bench press, and $6.51 \mathrm{~kg} / \mathrm{kg}$ for the deadlift. For comparison, the average values of the six heavyweight powerlifters reported previously were $6.95 \mathrm{~kg} / \mathrm{kg}, 4.84 \mathrm{~kg} / \mathrm{kg}$, and $6.33 \mathrm{~kg} / \mathrm{kg}$, respectively (1). Thus, the powerlifter in this case study not only had high levels of absolute muscular strength but also had high levels of relative strength per unit SM, particularly in the squat.

\subsection{Muscle Architecture}

The muscle thickness, pennation angle and fascicle length of the vastus lateralis was $4.2 \mathrm{~cm}, 30$ degrees and $8.2 \mathrm{~cm}$, respectively. A previous study reported that seven heavyweight powerlifters averaged $3.7 \mathrm{~cm}$ for muscle thickness, 24 degrees for the pennation angle and $9.1 \mathrm{~cm}$ for fascicle length in the vastus lateralis (16). On the other hand, mean values of untrained young men were 2.3 - 2.4 cm for muscle thickness, 18 - 20 degrees for pennation angle and $6.9-7.2 \mathrm{~cm}$ for fascicle length in the vastus lateralis $(17,18)$. The powerlifter in the current investigation had a greater pennation angle of the vastus lateralis compared to previously reported heavyweight powerlifters (16) and untrained men $(17,18)$. Kawakami and colleagues (9) studied approximately 700 individuals (aged 3 - 94 years, including normal individuals and highly trained bodybuilders) and reported a range of muscle thickness (1.2 $4.5 \mathrm{~cm}$ ) and pennation angles (9 - 33 degrees) of the vastus lateralis. In this case study, the lifter approached the maximal values reported by Kawakami et al. (9) for both muscle thickness and pennation angle. These findings suggest that a very large vastus lateralis may be more related to an increase in pennation angle rather than fascicle length.

\section{Conclusions}

The current strongest raw powerlifter in the world had greater values of fat-free mass and total SM compared to previously published values within the same population. When calculating the powerlifting performance per unit SM, this powerlifter not only had high levels of absolute strength but also had high levels of relative strength per unit SM, particularly in the squat. Similarly, muscle thickness and pennation angle of the vastus lateralis were close to the highest values previously reported in the literature. These results suggest that this powerlifter may be very close to a physiologic limit with respect to muscle size and geometry.

\section{Acknowledgments}

We thank the powerlifter who participated in this study.

\section{Footnotes}

Conflict of Interests: No potential conflict of interest was reported by the authors.

Funding/Support: This study received no specific grant from any funding agency in the public, commercial or notfor-profit sectors.

\section{References}

1. Ye X, Loenneke JP, Fahs CA, Rossow LM, Thiebaud RS, Kim D, et al. Relationship between lifting performance and skeletal muscle mass in elite powerlifters. J Sports Med Phys Fitness. 2013;53(4):409-14. [PubMed: 23828289].

2. Kondo M, Abe T, Ikegawa S, Kawakami Y, Fukunaga T. Upper limit of fat-free mass in humans: A study on Japanese Sumo wrestlers. Am J Hum Biol. 1994;6(5):613-8. doi: 10.1002/ajhb.1310060509. [PubMed: 28548340].

3. McArdle WD, Katch FI, Katch VL. Exercise physiology: nutrition, energy, and human performance. Lippincott Williams and Wilkins; 2010.

4. Midorikawa T, Sekiguchi O, Beekley MD, Bemben MG, Abe T. A comparison of organ-tissue level body composition between college-age male athletes and nonathletes. Int J Sports Med. 2007;28(2):100-5. doi: 10.1055/s-2006-924139. [PubMed: 17133285].

5. Abe T, Buckner SL, Dankel SJ, Jessee MB, Mattocks KT, Mouser JG, et al. Skeletal muscle mass in human athletes: What is the upper limit? Am J Hum Biol. 2018;30(3). e23102. doi: 10.1002/ajhb.23102. [PubMed: 29356191] 
6. Erlandson MC, Lorbergs AL, Mathur S, Cheung AM. Muscle analysis using PQCT, DXA and MRI. Eur J Radiol. 2016;85(8):1505-11. doi: 10.1016/j.ejrad.2016.03.001. [PubMed: 27005009].

7. Sanada K, Kearns CF, Midorikawa T, Abe T. Prediction and validation of total and regional skeletal muscle mass by ultrasound in Japanese adults. Eur J Appl Physiol. 2006;96(1):24-31. doi: 10.1007/s00421-0050061-0. [PubMed: 16235068].

8. Franchi MV, Atherton PJ, Reeves ND, Fluck M, Williams J, Mitchell WK, et al. Architectural, functional and molecular responses to concentric and eccentric loading in human skeletal muscle. Acta Physiol (Oxf). 2014;210(3):642-54. doi: 10.1111/apha.12225. [PubMed: 24387247].

9. Kawakami Y, Abe T, Kanehisa H, Fukunaga T. Human skeletal muscle size and architecture: variability and interdependence. Am J Hum Biol. 2006;18(6):845-8. doi: 10.1002/ajhb.20561. [PubMed: 17039483].

10. Abe T, Kondo M, Kawakami Y, Fukunaga T. Prediction equations for body composition of Japanese adults by B-mode ultrasound. Am J Hum Biol. 1994;6(2):161-70. doi: 10.1002/ajhb.1310060204. [PubMed: 28548275].

11. Abe T, Loenneke JP, Thiebaud RS, Fukunaga T. Age-related site-specific muscle wasting of upper and lower extremities and trunk in Japanese men and women. Age (Dordr). 2014;36(2):813-21. doi: 10.1007/s11357013-9600-5. [PubMed: 24243442]. [PubMed Central: PMC4039273].

12. Ando R, Taniguchi K, Saito A, Fujimiya M, Katayose M, Akima H. Validity of fascicle length estimation in the vastus lateralis and vastus inter- medius using ultrasonography.J Electromyogr Kinesiol.2014;24(2):21420. doi: 10.1016/j.jelekin.2014.01.003. [PubMed: 24485560].

13. Brozek J, Grande F, Anderson JT, Keys A. Densitometric Analysis of Body Composition: Revision of Some Quantitative Assumptions. Ann NYAcad Sci. 1963;110:113-40. [PubMed: 14062375].

14. Wilmore JH, Haskell WL. Body composition and endurance capacity of professional football players. J Appl Physiol. 1972;33(5):564-7. doi: 10.1152/jappl.1972.33.5.564. [PubMed: 4635917].

15. Parr RB, Hoover R, Wilmore JH, Bachman D, Kerlan RK. Professional Basketball Players: Athletic Profiles. Phys Sportsmed. 1978;6(4):77-87. doi: 10.1080/00913847.1978.11710700. [PubMed: 27432501].

16. Brechue WF, Abe T. The role of FFM accumulation and skeletal muscle architecture in powerlifting performance. Eur J Appl Physiol. 2002;86(4):327-36. [PubMed: 11990746].

17. Ema R, Wakahara T, Miyamoto N, Kanehisa H, Kawakami Y. Inhomogeneous architectural changes of the quadriceps femoris induced by resistance training. Eur J Appl Physiol. 2013;113(11):2691-703. doi: 10.1007/s00421-013-2700-1. [PubMed: 23949789].

18. Wakahara T, Ema R, Miyamoto N, Kawakami Y. Increase in vastus lateralis aponeurosis width induced by resistance training: implications for a hypertrophic model of pennate muscle. Eur J Appl Physiol. 2015;115(2):309-16. doi: 10.1007/s00421-014-3012-9. [PubMed: 25294665]. 